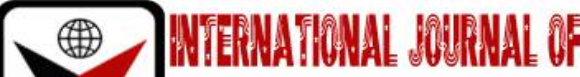

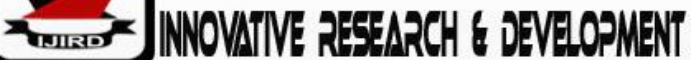

ISSN 2278-0211 (Online)

\section{The Nature of Coastal Erosion in the Ada-Foah Area in the Greater Accra Region of Ghana}

\author{
Emmanuel Agbenyegah Ayerteye \\ Tutor, Department of Social Studies, Mount Mary College of Education, Ghana \\ Agbedam Jacob Atteh \\ Tutor, Department of Social Studies, Ada College of Education, Ghana
}

\begin{abstract}
:
This paper seeks to find out the nature of coastal erosion in the Ada-Foah in the Greater Accra region of Ghana. In Ghana, the problem of coastal erosion in the Ada-Foah area has been an ongoing phenomenon which has affected several communities along the coast; with significant impacts, including loss of beaches and arable and buildable lands. This study employs a case study design and a qualitative approach. The study employed purposive and convenience sampling method in selecting respondents from the accessible population non-randomly based on what they can contribute. The instrument used in collecting data from the study participants were the interview schedule, observation and documentary analysis. There was a pilot interview which ensured good questions. The research was conducted in a natural setting using the local dialect, Dangme, to promote the reality of the respondents' experiences more accurately. Narrative descriptions were used in the analysis and presentations of data. The result was then integrated into an in depth, exhaustive description of the phenomenon of coastal erosion in Ada-Foah area.
\end{abstract}

Keywords: Coastal erosion, beaches, coastline, waves, tidal, current submergence, shoreline retreat, accretion, recession

\section{Background to the studies}

Coastal erosion is one of the most prevalent global environment problems affecting many coastal communities around the world, causing damage to life and property as well as the coastal infrastructure (Tripathy \& Sunakars, 1999). As observed by Abbot (1999) the world's coastlines are suffering major impact not only from tsunamis but also from smaller storms and everyday coastal process (Abbot, 1999). According to the World Meteorological Organization (WMO), the 2003, Atlantic hurricane season saw the development of sixteen (16) named storms which is well above 1944 and 1996 average of 9.6 with marked increase since the mid- 1990s. The pattern continued in 2004, which saw devastating hurricanes sweep into the Caribbean and the Gulf of Mexico, where they claimed some 2000 lives and left a trail of destruction (WMO, 2003). In 2003, Sri Lanka was hit by a cyclone that caused severe flooding, resulting in in the loss of at least 250 lives (Larson \& Simons, 2005).

In West Africa, the coastline has also shown the result of coastal erosion (Gilbert, 1982). For example, the lowlying atoll nations like the Maldives, Benin, Ghana, Lome in Togo, Lagos in Nigeria and other beach settlements along the West African coast risk their very existence and areas like Keta, Elmina, Nkotompo all in Ghana, have already been subjected to extreme vulnerability to coastal inundation and extreme weather events that are likely to see their vulnerability increase.

Ada-Foah is one of the coastal communities in Ghana mostly affected by coastal erosion with implications for the livelihoods of the people. Lately, the problem of coastal erosion in the area has become more alarming than ever. The land is creeping in at a rapid rate leading to the destruction of properties, including houses, crops and livelihood activities. It is based on this background that the researcher set out to investigate the phenomenon of coastal erosion and assess its nature and effect on the livelihood of residents and the various strategies that these residents are adopting to cope with the problem.

\subsection{The Nature of Coastal Erosion}

From the 1960s, researchers began to study into the area of coastal erosion and came out with several views on the subject. For example, Strahler (1965) opines that when enormous waves break and throw tons of water against the shoreline, it brings about rapid erosion in the coastal communities. Settlements near the coasts, therefore, suffer several kinds of coastal erosion both of which degrade the coastal environment and change the natural ecosystem. Coastal erosion is the wearing away of land or the continuous removal of beaches or dune sediments by the action waves, tidal currents, wave currents, or drainage (Strahler, 1965). Waves, generated by storms, wind, or fast moving motor craft, cause coastal erosion, which may take the form of long term losses of sediment made of rocks, dirt and earth, or merely the temporary 
redistribution of coastal sediments so that erosion in one location may result in accretion nearby (Wikipedia, 2008). Coastal erosion is not only caused by the action of breaking waves on the land but also by wind (Pirazzoli, Regnauld \& Lemasson, 2004; Regnauld, Pirazzoli, Morvan, \& Ruz, 2004). Erosion by wind action occurs mostly on beaches and deserts, because there is no continuous vegetation or plants cover (Exline, Jones, Vogel, Holtzclaw, Miller, Wellnitz \& Simons, 2001). Its long-term trend is shoreline retreat which is the landward encroachment of the sea.

Coastal erosion and shoreline retreat occur in several ways including hydraulic action, abrasion, corrosion and attrition (http://en.wikipedia.org/wiki/Coastal_erosion). Hydraulic action is the process by which the pounding of the waves, and the compression of water into cracks in the rock's surface, causes the rock to weaken and break. Abrasion is the process where sand and other debris are picked up by waves and scrap along the coastline. Corrosion is when certain types of cliff erode by the weak acids in the sea and Attrition is when the waves cause rocks and pebbles to bump into each other and break. Coastal erosion may also be short-term or long-term in nature. The short-term erosion is caused by storms or climate cycles without causing a permanent change in the position of the shoreline. While the area usually recovers, a full erosion and recovery cycle can take several decades. Natural dune repair is more likely to happen on dunes with good cover of native sand binding grasses. The long-term erosion on the other hand is a permanent change in the position of the shoreline, for example, through erosion caused by sea-level rise.

As the beach is constantly pounded by waves it eventually breaks fragments of ground and rock into sand particles, because there is no continuous groundcover on the beach (Strahler, 1965). These particles are then blown from side to side along the coast leading to erosion. Eventually, the land is gone forever and water takes its' place. (Glanz,1982; Tripathy \& Sunakars, 1999). But no matter how hard a coast is hit by waves, it also depends on lunar tides and differences in water density (Abbot, 1999). Coastal erosion is therefore, a natural or man-made phenomenon with sudden disruption of normal life of coastal communities that most people are unaware of (Tripathy \& Sunakars, 1999). It is an important hazard of great concern in coastal urbanized areas (Appendini \& Fischer, 1998). However, the limited understanding about its complex nature often leads to unwise use and development in the coastal areas and as such, its management and prevention is very difficult and costly to undertake.

Traditionally, public attention and concern for shoreline erosion has centered on events such as severe storms and hurricanes because of their dramatic nature; whereas chronic day-to-day erosion has received little attention (Abbot, 1999). The day to day cumulative losses over the years have significant impacts on the shoreline and the property there. This means, it is the day to day shoreline erosion process that reduces the protective cover of a beach, making the immediate property more vulnerable to extreme hazard events such as storms and hurricanes. As a major problem in recent times it is increasingly becoming impossible to predict precisely the nature or timing of such coastal erosion to construct barriers or buildings that resist its largest shocks. Coastal erosion, however, varies from coast to coast depending on the structure and type of materials that the coastal environment is made of (Galles \& Levine, 1999: Abbot, 1999). In an area where the material making the coast is susceptible to erosion, for instance, where the beach is made of sand, erosion is more rapid than an area with an underground parent rock. In times of relatively calm or moderate winds, waves do little erosion work but tend instead to build beaches and sand bars out and gravel.

For people to have always liked to continue to stay and work in the coastal areas depends on the nature of coastal erosion and because of its rich resources for their livelihood activities despite the numerous problems of coastal erosion (Oberlander \& Mullar, 1984). Depending on its nature, the coastal environment, however, poses difficulties and challenges to human settlement in hazards such as volcanic eruption, earthquake, hurricanes and other storms, rivers and coastal flood and coastal erosion (Adger, Hughes, Folke, Carpenter \& Rockstrom, 2005). These hazards can interrupt humans' activities to a great extent although they seldom deter humans from settling or developing an area if its resources are attractive (Bradshow, 1997; Abott, 1999). This means that the coastal dwellers cannot do without these coastal resources that provide them with all they need for survival hence, no matter what challenges they face as a result of these hazards did not prevent them from settling along the coast but rather developing skills to survive it.

De Blij and Muller (1993) posit that the nature of coastal erosion can be determined by uplifted and submergence coasts. The landscapes of uplifted coast carry the imprints of elevation by tectonic forces. These coastal zones have been uplifted faster than postglacial sea level rose. The result is such features as cliffs and wave-cut platforms which are raised above the present sea levels. While the coasts where the processes of aggravation dominate may also be uplifted, such depositional coastlines tend to lie in more stable lithospheres. There, the coastal environment is more rapidly eroded by erosion processes because the uplifted landforms are not as strong as the bedrock cliffs and wave-cut platforms (de Blij \& Muller, 1993). This shows that more coasts are drowned or submergence coast rather than uplifted. This submergence was caused greatly by rise in sea levels over the past thousand years. At the beginning the sea levels stood perhaps below its present average but as a result of changes in climatic factors, the sea levels have risen to submerge many coastal environments.

\section{Methodology}

\subsection{The Research Design}

This study employs a case study design and a qualitative approach with a non-probability sampling was technique. In the light of this, the study used a sample size of 30 participants. The study employed purposive and convenience sampling method in selecting the different categories of respondents from the accessible population. The current study selected respondents non-randomly based on what they can contribute. The instrument used in collecting data from the study participants were the interview schedule, observation and documentary analysis. In order to ensure validity the researcher based the items on the research instrument on the research questions. The researcher also pre-tested the 
instruments with colleagues and also showed them to the supervisor. The researcher modified the content of the instruments based on the assessment and suggestions of colleagues and the supervisor. Several questioning techniques were employed to stimulate responses. There was a pilot interview which ensured good questions. The research was conducted in a natural setting using the local dialect, Dangme, to promote the reality of the respondents' experiences more accurately.

The study employed the comparative method to compare one unit of information with another looking for recurring regularities and patterns in the data for categorization. In line with this, all interview records were read several times to obtain understanding for them. For each recorded response, significant phrases or sentences that pertained directly to the purpose and focus of the studies were identified. Meanings were then formulated from the significant statements. The formulated meanings were classified into categories allowing for some recurring regularities that cut across all the recorded responses. With the use of comparative method the researcher then compared these tentative categories to each other, and to other instances. This comparison was constantly done within and between levels until a result was arrived at. The categories were then subdivided. There were double checking to refine analysis and interpretations to ensure validity and reliability. Words were used instead of numbers to analyze data. Narrative descriptions were used in the analysis and presentations of data. The result was then integrated into an in depth, exhaustive description of the phenomenon of coastal erosion and its effect on livelihoods in Ada-Foah area (Taylor \& Bogdon, 1998 in Merriams, 1998).

\subsection{Ethical Considerations}

As this study utilized human participants, and in the interest of maintaining the integrity of the research, the researcher had made every effort to ensure that certain ethical issues were strictly addressed in respect of the privacy as well as the security of the participants. These issues were identified in advance so as prevent problems that could arise during the research process. Among the significant issues that were considered included consent, confidentiality and data protection. Thus, prior to commencing with the research, permission was obtained from each participant, who participated in the study. The names of the participants were secured. The objective, purpose and the significance of the study were all relayed to the participants before initiating the research process. All data collected from the participants were kept in a secure location.

\subsection{The Nature of Coastal Erosion at the Ada-Foah Community}

The first research question posed for this study sought to find out the nature of coastal erosion in the coastal community of Ada-Foah. In line with this, data were gathered from stakeholders in the study area. In all, 30 people participated in the study. They were made up of 20 residents, 4 chiefs, and one personnel each from the District assembly, the Community Radio Station, the VRA, the CDDF, the Department of Wildlife and the NADMO. The instruments employed to gather the data were field observations, interviews and documentary analysis. Field observations were conducted by the researcher in the study communities to observe the nature of coastal erosion and shoreline retreat. Interviews were then conducted with the 30 participants while available documentary sources were analyzed to obtain relevant data. The analysis of the data gathered through a combination of observation and documentary analysis revealed that coastal erosion and shoreline retreat in the Ada-Foah community takes the form of abrasion where the sand and other debris which build the beach are washed away by stormy waves and scrap along the shoreline. The nature of coastal erosion and shoreline retreat in the Ada-Foah area can also be described as a long term occurrence as there is permanent change of the shoreline through erosion caused by sea level rise and tidal storm. Participants in the communities affected share their observations and experiences about the phenomenon of coastal erosion.

In Azizanya, a traditional chief and a retired educationist commented that coastal erosion and shoreline retreat have occurred rapidly in the area and several communities have been washed away. According to him, coastal erosion used to be a gradual process when he was young. Pointing to a boat on the sea, about 200 meters from the shore, he said: "That is where we used to live some 43 years ago. Oh! Ajivo and old Azizanya are gone". When asked what has happened

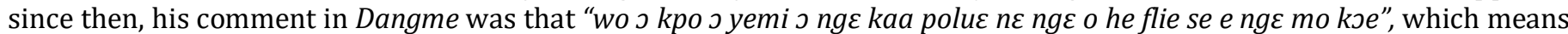
"the nature of coastal erosion is like a tsetse fly that is fanning your body but biting at the same time". He explained that during wave storm, the waves remove about $10 \mathrm{~m}$ of the land space away with everything on it and during the period of calm, it rebuilds only about $3 \mathrm{~m}$ to $4 \mathrm{~m}$ a year.

In another interview, the chief fisherman at Lolonyakope noted that the coastal erosion and shoreline retreat process "is like a thief who comes unannounced to kill, destroy and to take away everything you have". He said for instance that, the sea may be calm today with every economic activity going on but suddenly, there may be a change in its nature with destructive waves washing away the land and its properties. He lamented in Dangme that: "Hhm...! E nge nyakpe, I pa li no ne ma de po. Wa n $f_{\varepsilon \varepsilon}$ n ta". This literally means "It is wonderful. I don't know what to say again, everything we have is gone". He further explained that the nature of coastal erosion in Ada-Foah is vigorous at times with rapid abrasive effect on the coast.

At Otrokper, an officer of the Volta River Authority comment on the nature of coastal erosion and shoreline retreat in Ada-Foah area. In comment he said: "The nature of coastal erosion of late is beyond our understanding". "Ahhh! No! It was not like this before" he exclaimed, "The sea is now eating the land at a faster rate than ever". He explained that storms formerly lasted between two and three days but nowadays it does go beyond a week especially during the months July, August and September when it is at its peak. Another participant who is an officer of NADMO but resident at Otrokper observed that during the process of shoreline retreat, the beach is raised by the pounding waves making it easy to be washed away. "My family house used to be there," he said, climbing up a crumbling fort wall to point out a cluster of fishing 
canoes bobbing in the waves several hundred yards offshore. "The sea destroyed our house, so we moved to settle here". Also at Totopey, Kofi Mensah, a fisherman who participated in the interviews pointed to the submerged concrete walls of a house and said: "This used to be my room," "Yes, this would have been the roof." On his part the chief of Totopey expressed fear that the settlement might soon be washed away completely by erosion.

Observations from the field work point to the fact that coastal erosion and shoreline retreat in the area is an ongoing phenomenon which is gradually eating away the community of Ada-Foah. The land is washing off at a rapid rate, destroying houses, farms and businesses as well as eroding the livelihood opportunities in the area. The nature of coastal erosion in Ada-Foah is severe in the low lying communities which include Azizanya, Ayigbo, Lolonyakope with a remarkable change in shape of the coastline, i.e., from a regular, smooth coastline formerly to a very irregular coastline now. Further observations indicated that there are both land recession and accretion processes going on in Ada-Foah with the recession rate higher than accretion. Thus, during the period of calm, the beach seems to rebuild itself but at a shorter rate than the erosion that occurs during wave storms.

Based on extensive comparison of photographs and conversation with the local residents, it was observed that the coastline has moved inland over some 50 meters during the period of 1998 and 2008. Figure 4.1 shows some photographs of the Dangme East District Assembly Office which were taken in 1998 and on November 5, 2008. The retreat of the coastline is visible from the photograph below.

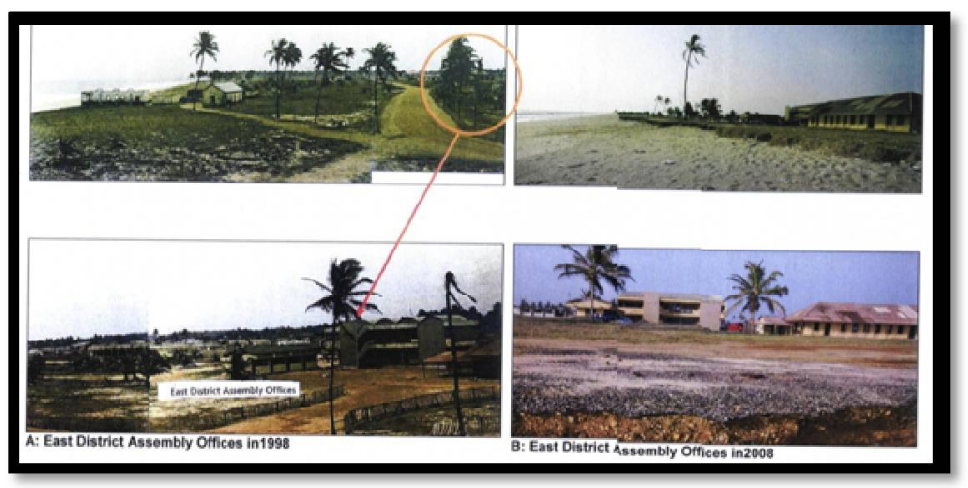

Plate 4.1: Coastal Erosion at the District Assembly Area Source: Extracted from Alkyon and Ecorem, 1998 And 2008

The plate in Figure 4.1 labelled A was taken in 1998 to capture the land distance from the sea to the district administration as put in the ring with the arrow showing. In the year 2008, another photograph was taken on the same spot as labelled B. At this time, almost all the land between the District Assembly and the sea has been washed away as a result of coastal erosion and shoreline retreat. Analysis of document from the district assembly indicated that since the $20^{\text {th }}$ century, coastal erosion had been affecting the shoreline of Ada-Foah most particularly on the shores extending from the mouth of the Volta River. The erosion rate since 1937 was also constantly increasing as could be seen from Table 4.1 .

\begin{tabular}{|c|c|c|}
\hline No. & Period & Average Erosion rate (Annual) \\
\hline 1 & $1939-1976$ & $2-2.5 \mathrm{~m}$ \\
\hline 2 & $1979-1981$ & $3-4 \mathrm{~m}$ \\
\hline 3 & $1981-1985$ & $8-10 \mathrm{~m}$ \\
\hline 4 & $1985-2004$ & Appr. $10 \mathrm{~m}$ \\
\hline
\end{tabular}

Table 4.1: Erosion Pattern in Ada-Foah from 1937 to 2004

Source: Ministry of Housing - Profile: Ada Sea Defense and Volta Estuary Project - (2004)

From Table 4.1 the rate of shore line retreat was approximately 2-8 meters from1939 to 1981 and has increased over the years to 10 meters per year in the period 1985 to 2004 . This is supported by the coastal map in Figure 4.2 showing the distance of land loss and properties consumed by the sea. 


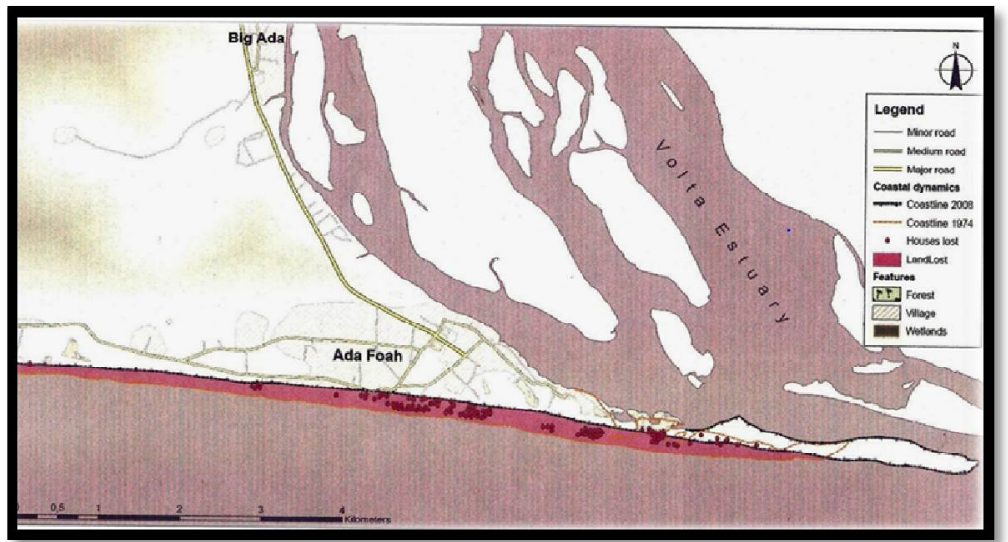

Plate 4.2: Loss of Land and Buildings at Ada-Foah Due to Coastal Erosion in the Last Thirty-Five (35) Years

Source: Extracted From Alkyon, 1998 and Ecorem, 2008

From plate 4.2 it is seen that erosion was ongoing along the coast over 35 years ago with over five kilometers of land and buildings lost to the sea. A data collected by the Community Directed Development Foundation (CDDF) between July and December, 2006 at three separate points namely Lolonyakope, Cemetery Area and Otrokper has been further analysed by the researcher and presented as shown in Table 4.2 below.

\begin{tabular}{|c|c|c|}
\hline Lolonyakope & Cemetary Area & Otrokper \\
\hline $\mathrm{A} 1-598$ & $\mathrm{~B} 1-164$ & $\mathrm{C} 1-387$ \\
\hline $\mathrm{A} 2-275$ & $\mathrm{~B} 2-127$ & $\mathrm{C} 2-135$ \\
\hline $\mathrm{A} 3-807$ & $\mathrm{~B} 3-173$ & $\mathrm{C}-163$ \\
\hline $\mathrm{A} 4-511$ & $\mathrm{~B} 4-53$ & $\mathrm{C} 4-144$ \\
\hline $\mathrm{A} 5-517$ & $\mathrm{~B} 5-126$ & $\mathrm{C} 5-144$ \\
\hline $\mathrm{A} 6-162$ & $\mathrm{~B} 6-27$ & $\mathrm{C} 6-223$ \\
\hline $\mathrm{A} 7-422$ & $\mathrm{~B} 7-137$ & $\mathrm{C} 7-230$ \\
\hline $\mathrm{A} 8-598$ & $\mathrm{~B} 8-137$ & $\mathrm{C}-252$ \\
\hline $\mathrm{A} 9-164$ & $\mathrm{~B} 9-105$ & $\mathrm{C} 9-376$ \\
\hline $\mathrm{A} 10-438$ & $\mathrm{~B} 10-32$ & $\mathrm{C} 10-384$ \\
\hline $\mathrm{A} 11-645$ & $\mathrm{~B} 11-76$ & $\mathrm{C} 11-252$ \\
\hline $\mathrm{A} 12-587$ & $\mathrm{~B} 12-14$ & $\mathrm{C} 12-58$ \\
\hline $\mathrm{A} 13-589$ & $\mathrm{~B} 13-74$ & $\mathrm{C} 13-28$ \\
\hline $\mathrm{A} 14-612$ & $\mathrm{~B} 14-99$ & $\mathrm{C} 14-134$ \\
\hline $\mathrm{A} 15-498$ & $\mathrm{~B} 15-91$ & $\mathrm{C} 15-191$ \\
\hline $\mathrm{A} 16-325$ & $\mathrm{~B} 16-203$ & $\mathrm{C} 16-363$ \\
\hline $\mathrm{A} 17-386$ & $\mathrm{~B} 17-47$ & $\mathrm{C} 17-164$ \\
\hline $\mathrm{A} 18-248$ & $\mathrm{~B} 18-172$ & $\mathrm{C} 18-270$ \\
\hline $\mathrm{A} 19-346$ & $\mathrm{~B} 19-79$ & $\mathrm{C} 19-169$ \\
\hline $\mathrm{A} 20-387$ & $\mathrm{~B} 20-124$ & $\mathrm{C} 20-253$ \\
\hline \hline Average $:$ 426cm & $95 \mathrm{~cm}$ & $197 \mathrm{~cm}$ \\
\hline $43 \mathrm{~m}$ & $9.5 \mathrm{~m}$ & $19.5 \mathrm{~m}$ \\
\hline
\end{tabular}

Table 4.2: A Measure of Average Land Loss by the CDDF at Ada-Foah from July to December, 2006 Source: Community Directed Development Foundation (CDDF) - 2006

Source: Extracted From Ecoremnv - E02/0121.002.R1 - 15/12/2008 - SH/FL/ADR

In Table 4.2 the area was demarcated into three segments namely Lolonyakope, Cemetery Area and Otrokper with pegs A, B, C respectively. Each point had 20 pegs with distance of land loss to the sea read every two weeks. The total distance of land loss to the sea at pegs A, B and C was calculated for all the segments as shown in Table 4.2 above. The average land loss to the sea was then calculated at each segment and converted from centimeters to meters to know the average land loss each year. Also, the distributions in Table 4.2 indicate that the extent of erosion along the coast was not even but rather more intense at some places than other places. Lolonyakope had higher level of coastal erosion and shoreline retreat probably because of the fact that the area is low lying as compared to Cemetery area and Otrokope.

It could be deduced from the above that both accretion and recession occur along the shore line of Ada-Foah but the rate of recession is much greater than accretion especially between the months of June and August when the coast experiences stormy sea. Beach accretion however, takes place from the month of November to early March. From the table above it could be observed that the erosion pattern along the coastal communities of Ada-Foah keep on increasing every now and then doubling at every ten year intervals with some of the years experiencing coastal erosion more severely than 
others. It could be inferred from the above distribution that erosion has been ongoing along the coast of Ada-Foah for more than 50 years now.

\section{Summary of Findings}

The analysis of the data gathered for the study has brought out the following findings:

\subsection{The Nature of Coastal Erosion in Ada-Foah}

Coastal erosion and shoreline retreat is a widespread phenomenon along the coast of Ada-Foah and is gradually eating away communities in the area. Coastal erosion and shoreline retreat in Ada-Foah is also long term in nature. It results in a remarkable change in the shape of the coastline, from a formerly regular, smooth to an irregular coastline now. Coastal erosion and shoreline retreat in the Ada-Foah community takes the form of abrasion - a process by which the sand and other debris which build the beach are washed away by stormy waves and scrap along the shoreline. This abrasive nature of coastal erosion in the Ada-Foah area is more severe in the low lying communities including Azizamya, Ayigbo, and Lolonyakope. The rate of coastal erosion and shoreline retreat in the study area is variable with time. Certain years experiences more erosion than others. Thus the remaining land mass between the ocean and the Volta River varies in length. In some portions, it may only take a maximum of 3 to 4 years to be eroded. There is however, both accretion and recession occurring along the shore line of Ada-Foah with the recession rate higher than accretion, especially between the months of June and August when the coast experiences stormy waves. Beach accretion however, takes place from the month of November to early March.

\subsection{Discussions of Findings}

The nature of coastal erosion and shoreline retreat in the Ada-Foah area and the rapid rate at which the sea is eroding the land indicates that coastal erosion and shoreline retreat has become a major threat to the future existence of Ada-Foah and its surrounding communities. Considering the current shoreline retreat rate of about $10 \mathrm{~m}$ a year, it may be estimated that about 5km of Ada-Foah land has already been washed away by the sea. This shows that in some fifty years to come, Ada-Foah will be no more considering the land space that is left between the Volta River and the sea. This is expected to put the communities in the area at risk.

\section{Conclusion}

Coastal erosion results from the cumulative impact of a wide range of natural and human-induced factors, none of which may be considered as the single cause for erosion. It is a phenomenon which has emanated in an abrasive form and has affected every livelihood opportunity in the Ada-Foah area. For instance, the importance of coastal tourism in the AdaFoah area implies an interest in the maintenance of beaches. However, coastal erosion and shoreline retreat have led to the reduction of the beaches, destruction in saltwater fishing, the reduction in migratory bird as well as the reduction in bird viewing. These resources formed an important livelihood opportunity for about one third of the youth population, especially the coastal households in the Ada-Foah area.

\section{Recommendations}

In line with the findings of this study, the following recommendations are made for addressing the problem of coastal erosion and shoreline retreat in Ada-Foah.

- The government in collaboration with NGOs should construct sea-defense systems to prevent further erosion and shoreline retreat as well as protect the people, their landed properties and livelihood opportunity from the vagaries of coastal erosion and shoreline retreat. This may include systems such as seawalls, rock revetments and bulkheads which protect the land from further erosion or systems such as groynes and offshore breakwaters which protect the land by promoting beach build-up.

- The study recommends dredging of the estuary to widen and deepened it, and if possible, to convert it into a mini habour to ease the movements of fishermen each time they embarked on fishing activities through the estuary.

- The study recommends a main habour to be constructed in Ada-Foah. This will not only protect the land from further erosion but also restore the livelihoods of residents as well as promoting diverse economic activities in the area.

\section{Areas for Further Research}

In view of the limitations of the study, any future research should incorporate socio-economic survey of the affected communities in order to understand demographic issues, household income levels and alternative livelihood issues within the Ada-Foah community. Future studies should also explore diversification as a potential coping strategy and make recommendations for the development of this potential.

\section{References}

i. Abbot, P. L. (1999). Natural Disaster. Boston: McGraw- Hills.

ii. Adger, W. N., Hughes, T., Folke, C., Carpenter, S., \& Rockstrom, J. (2005). Social-ecological resilience to coastal disasters. Science 30(9), 1036-1039.

iii. Agarwala S., Ota T., Ahmed A.U., Smith J., \& Aalst M van (2003). Development and climate change in Bangladesh: focus on coastal flooding and Sundarbans. Paris: OECD (Organization for Economic Co-operation and Development). 
iv. Alkyon. (1998). Sea defence in Ada, Ghanam, report A208R3r1

v. Appendini, C. M., \& Fischer, D. W. (1998). Shore and Beach. shore beach, 66(4) 5-8

vi. Bradshow, M. (1997). World Regional Geography: The New Global Order. New York: macmillan.

vii. Castillo, J. (2009), Probability Sampling and Randomization. Retrieved on September 7, 2010 from:< http://www.experiment-resources.com/probability-sampling.html> de Blij, H. J. \& Muller, A. R. (1993). Human Geography: Culture, Society and Space (4th Ed.) New York: Wiley and Sons.

viii. Ecorem NV. (2010). Sea turtle monitoring for ADA FOAH Coastal Protection Project. - Monitoring proposal

ix. Exline, J. D., Jones, L. C., Vogel, C. G., Holtzclaw, F., Miller, S., Wellnitz, T. R. \& Simons, B. B. (2001). Science Explorer: Focus on Earth Science. California: Prentice Hall.

x. Galles J. R. \& Levine A. (1999). Sociology. An Introduction. New York: MacGraw-Hills.

xi. Gilbrt, A. E. (1982). Regional Geography of West Africa. London: Macmillan.

xii. Islam, R. M. (2008). Towards institutionalization of global ICZM efforts. In: R. R Krishnamurthy (Ed.). Integrated coastal zone management. Singapore: Research Publishing Services.

xiii. Glantz, M. A. (1997). The Global Challenge. In R. Jackson, (Ed). Global Issues. Connecticut: MacGraw-Hills.

xiv. Larson, M. H. \& Simons, G. F. (2005). Natural Disasters. Are they getting worse? Awake Journal. New York: Watchtower.

xv. MoWR (2006). Coastal development strategy. Water Resources Planning Organizations, Government Of People's Republic of Bangladesh. Ministry of Water Resources, 12(1), 4-5.

xvi. Oberlander, J. M. \& Muller, A. R. (1984). Physical Geography Today: A Portrait of a Planet. New York: McGraw-hills.

xvii. Pirazzoli, P.A., Regnauld H. \& Lemasson, L. (2004). Changes in storminess and surges in western France during the last century. Mar. Geol., 2(10), 307-323.

xviii. Regnauld, H., Pirazzoli, P.A., Morvan G. \& Ruz, M. (2004). Impact of storms and evolution of the coastline in western France. Mar. Geol., 2(10), 325-337.

xix. Strahler, A. S. (1965). Physical Geography of West Africa. London: John Wiley and Son.

xx. Tripathy, S. N. \& Sunakars, P. (1999). Fundamentals of Environmental studies. New Delhi: Vrinda Publication.

xxi. Taylor, S. J., \& Bogdan, R. (1998). Introduction to qualitative research methods (3rd Ed.). New York: John Wiley.

xxii. Wikipedia. (2008). Coastal erosion. Retrieved on April 12 2010. From http://en.wikipedia.org/wiki/Coastal_erosion.

xxiii. WMO, (2003). Proceedings of the Fifth WMO International Workshop on Tropical Cyclones (IWTC-V). WMO Rep., Geneva, Switzerland, 31 pp. 